\title{
Special Section: Addressing Behaviours of Concern
}

Michael Arthur-Kelly

It is a singular pleasure to introduce this issue of AJSE with a special section on addressing behaviours of concern. Our first paper comes from George Sugai and his colleagues, and both reprises and extends the excellent material George shared with us at the 2015 National Conference in Fremantle. As you read this paper, note the focus on key principles for capacity building in complex systems of support and consider the direct implications for your work in schools and jurisdictions. Our second paper is contributed by Hank Bohanon and colleagues and articulates how these principles and related aspects of implementation science underpin school improvement in secondary settings and the various ways this can occur to ensure a comprehensive approach to positive behaviour support.

Our third paper, by Sue O'Neill, then moves into the pivotal area of teacher education and, more particularly, teacher efficacy in relation to classroom and behaviour support. As you read this study, consider how emerging teachers prepare for complex classrooms and, especially, the importance of evidence-based practices and communities of learners as a platform for sustained and regenerative teacher retention and development in diverse classrooms.

Iva Strnadová and colleagues then share some recent data on transitions for students with a range of needs, framed within an ecological systems perspective. By describing the perspectives of carers and teachers, several recommendations for an improved emphasis on the various transitions students experience are highlighted for our consideration going forward. Our final paper for this issue is contributed by Kathryn Crowe and Sharynne McLeod and centres our attention on the critical role of professionals in the advice they provide to parents of students with hearing loss. This paper neatly rounds off this issue by underlining the human ecology that is at the heart of all the work we do in striving to ensure the best possible education for all students, as well as collaborating effectively with families and caregivers who share this journey in a unique way.

My thanks to our various authors from around the world for sharing such strong papers, and to you, the readers, my good wishes for a feast of exemplary research-topractice reading and reflecting on your daily work to maximise meaningful outcomes for all students.

Michael Arthur-Kelly for the Editorial team. 